\title{
À margem da humanização? Experiências de parto de usuárias de uma maternidade pública de Porto Alegre-RS
}

| ${ }^{1}$ Clarissa Niederauer Leote da Silva Pedroso, ${ }^{2}$ Laura Cecilia López |

Resumo: $\mathrm{O}$ artigo reflete sobre as experiências de mulheres em relação à assistência ao parto numa maternidade pública de Porto Alegre-RS. Adota-se uma perspectiva dos direitos humanos, entendendo a humanização como uma garantia ampla de direitos das mulheres a uma parturição segura, socialmente amparada e prazerosa. Trata-se de um estudo qualitativo exploratório, que utilizou as técnicas de observação participante, entrevista semiestruturada e pesquisa documental. Aceitaram fazer parte da pesquisa 25 mulheres puérperas, com idades entre 18 e 38 anos. Os relatos das participantes e os registros de campo foram examinados por meio da análise de discurso. Como resultados, constatamos uma fragmentação das práticas tidas como "humanizadoras", atreladas a protocolos de procedimentos no manejo do parto e, muitas vezes, à inflexibilidade perante eles. A supervalorização de tecnologias/práticas intervencionistas no corpo da mulher, assim como as hierarquias entre profissionais e usuárias apareceram nos relatos e nas observaçóes. Sentimentos e sensaçóes das mulheres em relação ao parto pareciam não ser contemplados e ficavam à margem do cuidado. Identificaram-se práticas de violência obstétrica, que muitas vezes eram banalizadas pelas próprias mulheres em consonância ao que elas esperavam de um atendimento público. Essas situaçóes parecem reforçar hierarquias reprodutivas, deixando essas gestantes “à margem da humanização”.

> Palavras-chave: parto humanizado; saúde da mulher; hierarquias reprodutivas.

\author{
1 Universidade do Vale do Rio \\ dos Sinos. São Leopoldo-RS, \\ Brasil (cclarissa.fisioterapeuta@ \\ gmail.com). \\ 2 Universidade do Vale do Rio \\ dos Sinos. Programa de Pós- \\ Graduação em Saúde Coletiva. \\ São Leopoldo-RS, Brasil \\ (lauracl1975@gmail.com).
}

Recebido em: 16/03/2017 Aprovado em: 08/09/2017 
O cenário brasileiro contemporâneo da assistência ao parto é complexo, apresentando marcantes dimensôes tecnocráticas, na medida em que sáo supervalorizadas e hierarquizadas as práticas médicas intervencionistas. Com uma visão rotineira de atendimentos que leva ao mau uso de tecnologias disponíveis e desvaloriza as recomendaçóes de evidências científicas existentes no campo, geram-se práticas desnecessárias na assistência às gestantes, que contribuem para a persistência de altas taxas de morbimortalidade materna e perinatal (WHO, 1996; LEAL et al., 2014). Ao mesmo tempo, existem dimensôes transformativas que tensionam de diferentes maneiras modelos e açóes em saúde, guiadas pelo polissêmico conceito de humanização (DESLANDES, 2004). Nesse sentido, também cresce, tanto socialmente quanto nas pesquisas acadêmicas, o uso do conceito de violência obstétrica para denotar e denunciar as práticas abusivas sofridas pelas mulheres no quadro da lógica tecnocrática e das hierarquias reprodutivas, que se expressam nas desigualdades de direitos na intersecção de gênero com outros marcadores sociais, como classe, raça, idade, orientação sexual (MATTAR; DINIZ, 2012).

Dentro da discussão atual sobre um modelo humanizado de assistência ao parto, destacamos a proposta da antropóloga Davis-Floyd (1994), que analisa os processos contemporâneos de parto e nascimento, a partir de modelos e rituais dessa assistência. Segundo a autora, o modelo tecnocrático de nascimento se tornou hegemônico no Ocidente com a institucionalização do parto nos hospitais, correspondente a uma sociedade industrial cada vez mais caracterizada como tecnocrática, na medida em que supervaloriza e se organiza de maneira hierarquizada em torno das suas tecnologias. Nessa via, a medicalização de nascimento constitui o hospital como uma indústria de alta tecnologia, destinada à produção de "bebês perfeitos", com uma legitimidade inquestionável dos procedimentos médicos (DAVIS-FLOYD, 1994; HELMAN, 2009). A supervalorização e a utilização maciça de tecnologias em favor de uma suposta segurança da parturiente e do bebê acabaram colocando em segundo plano as experiências singulares das mulheres e sua autonomia em relaçáo à gravidez e ao parto (DOMINGUES et al., 2004).

O modelo humanizado surge no próprio Ocidente como um movimento de reação aos excessos da tecnocracia, apresentando uma concepção holística do 
corpo e da gravidez, novas formas de vivenciar o parto, e que, consequentemente, passou a disputar o seu lugar de legitimidade no campo biomédico (TORNQUIST, 2004). Traz a ideia de conexão da gestante com múltiplos aspectos pessoais, do seu corpo, família, sociedade, saúde e com os profissionais de saúde, e reconstrói uma noção fisiológica do parto (DAVIS-FLOYD, 2001).

No Brasil, nos últimos anos, há propostas de humanização, a fim de garantir uma assistência menos intervencionista, baseada em evidências científicas sobre riscos e benefícios de determinadas práticas para a saúde da mulher e do bebê, na participação ativa da mulher e com maior ênfase nos aspectos socioculturais e emocionais da parturição (DOMINGUES et al., 2004; SEIBERT et al., 2005). Existem diversas estratégias governamentais que buscam qualificar a assistência à saúde materno-infantil, como é o caso da implementação da Estratégia Rede Cegonha - ERC (BRASIL, 2011) e a adesão às "boas práticas de atenção ao parto e ao nascimento", estipuladas pela Organização Mundial da Saúde desde a década de 1990 (WHO, 1996). Além do âmbito governamental, a humanização do parto vem sendo discutida na sociedade civil, que tem se mobilizado na busca pelos direitos da mulher e do recém-nascido (RATTNER et al., 2010). Aliado a isso, pesquisas são realizadas com o objetivo de analisar o cenário obstétrico brasileiro, como o estudo epidemiológico Nascer no Brasil, realizado nos anos 2012-2013 (LEAL; GAMA, 2014); a assistência ao parto em diversos locais e a percepção das mulheres em relação à mesma (DOMINGUES et al., 2004; MORAIS, 2010; VOGT et al., 2011; SANTOS; PEREIRA, 2012; LEAL et al., 2014), entre outras temáticas.

Nesse cenário, o presente artigo explora as particularidades locais das experiências de usuárias de uma maternidade pública na cidade de Porto Alegre/ RS. A perspectiva que nos guia é a dos direitos humanos (DINIZ, 2001), sendo que a humanização do parto é entendida como uma garantia ampla de direitos das mulheres a uma maternidade "voluntária, segura, socialmente amparada e prazerosa” (MATTAR; DINIZ, 2012, p. 107). Entendemos também a humanização, seguindo Ayres, como um ideal de construção "dos diversos sujeitos no contexto da organização das práticas de atenção à saúde, promovida por interaçôes sempre mais simétricas, que permitam uma compreensão mútua entre seus participantes e a construção consensual dos seus valores e verdades" (AYRES, 2005, p. 558). 
Como ressalta Deslandes (2004, p. 13), "as ideias de humanização como antítese da violência e da incomunicabilidade reforçam a posição estratégica das açôes centradas na ética, no diálogo e na negociação dos sentidos e rumos da produção de cuidados em saúde", podendo contribuir para a melhoria da atenção prestada. Porém, existem alguns pontos das discussóes em torno das práticas que são intituladas como "humanizadoras" que merecem maior reflexão. Principalmente, os que dizem respeito a mudanças culturais e institucionais baseadas numa relação mais simétrica entre profissionais e usuários, que só poderiam ser alcançadas através da valorização das expectativas e demandas dos usuários, reconhecendo sua autonomia e legitimidade (DESLANDES, 2004).

Nesse sentido, nossa hipótese é que, embora possamos perceber certas práticas "humanizadoras" no cenário analisado, o modelo que as orienta ainda continua sendo o tecnocrático, permeado por hierarquias entre os profissionais e as gestantes. Sentimentos e sensaçôes das mulheres em relação ao parto parecem não ser contemplados e ficam à margem do cuidado.

\section{Percurso metodológico}

Trata-se de uma pesquisa qualitativa exploratória, resultante da dissertação do mestrado em Saúde Coletiva da primeira autora, cujo universo empírico foi uma maternidade pública da cidade de Porto Alegre, RS. O hospital é totalmente dedicado ao Sistema Único de Saúde - SUS, que oferece serviços nas áreas de ginecologia e obstetrícia. Aproximadamente 500 partos mensais eram realizados na época da pesquisa.

Os sujeitos participantes dessa pesquisa foram mulheres puérperas que receberam assistência durante o trabalho de parto, parto e pós-parto nessa instituição. Foram incluídas tanto as gestantes de risco habitual quanto as gestantes de alto risco, permitindo um aprofundamento do olhar sobre essas experiências em diferentes contextos de interação com os profissionais da saúde.

Inicialmente, foi previsto a seleção de dez mulheres puérperas que estivessem internadas no alojamento conjunto da maternidade. É importante salientar que na pesquisa qualitativa o universo empírico prevê um número de pessoas, porém, este número não é rígido. Ele é definido pela própria saturação ou recorrência de dados, ou seja, pelo momento no qual se observa que a busca por mais sujeitos não acrescenta informações novas à investigação (VICTORA et al., 2000). 
Os critérios para a seleção das pessoas a ser entrevistadas foram elaborados no contexto da observação, a fim de captar sujeitos que pudessem expressar uma diversidade de situações, para contemplar o objeto de pesquisa (FLICK, 2009). Nesse sentido, não foram determinados a priori critérios de escolha das mulheres.

A pesquisa ocorreu entre novembro de 2014 e janeiro de 2015. Foram utilizadas as técnicas de observação participante (para acompanhar rotinas, práticas e interaçóes na assistência desde o setor da emergência até o alojamento conjunto), entrevista semiestruturada (para aprofundar o diálogo com as puérperas) e pesquisa documental (para indagar nos prontuários dessas mulheres). Inicialmente, foi realizada observação na emergência e no centro obstétrico durante quatro dias não consecutivos, nos turnos da manhã e da tarde. Posteriormente, no aloja mento conjunto, realizou-se as observaçôes concomitantemente com as entrevistas, durante o turno da tarde, em oito dias intercalados, sem incluir finais de semana.

A pesquisa documental foi feita com o intuito de coletar informaçôes dos prontuários para verificar dados referentes aos procedimentos e intervençôes praticados durante a assistência ao parto e nascimento das puérperas participantes da pesquisa.

As entrevistas foram gravadas e realizadas individualmente, junto ao leito. $\mathrm{O}$ roteiro utilizado para a entrevista continha questôes-chave que abordavam a percepção das mulheres quanto ao período gestacional, à assistência no prénatal, no trabalho de parto, parto e pós-parto imediato, ao acolhimento e à experiência em relação ao tipo de parto vivenciado. Todas as entrevistas foram posteriormente transcritas. O diário de campo foi utilizado para registrar o contexto das entrevistas e das observaçóes, a fim de documentar as experiências, sentimentos e impressôes de forma cronológica, procurando detalhar o mais fielmente possível tudo o que foi observado (VICTORA et al., 2000). ${ }^{1}$

A seguir, propomos analisar as experiências de parto dessas mulheres, relacionadas à assistência prestada na instituição. Adotamos uma estratégia de escrita que abarca o processo de assistência desde a entrada na maternidade até o pós-parto, para apontar aspectos positivos e nós problemáticos nos diferentes momentos. Triangulamos dados produzidos através das entrevistas, das observaçôes registradas em diário de campo e informaçôes levantadas dos prontuários, assim como a literatura produzida na área. Utilizamos o método de análise de discurso, que trabalha com a interpretação de linguagem de produçôes 
verbais e não verbais para compreensão dos processos sociais estabelecidos nos diferentes contextos do universo de pesquisa (CAREGNATO; MUTTI, 2006).

\section{Resultados e discussão}

Para a análise dos resultados com o aporte teórico da literatura, foram elaboradas categorias a partir de uma leitura detalhada e exaustiva das entrevistas e das anotaçóes do diário de campo. Inicialmente, realizou-se uma categorização vertical dos dados que possibilitou a identificação do perfil dos sujeitos participantes. Depois, através de uma releitura horizontal das entrevistas com as observações, criou-se categorizações fundamentadas na comparação das respostas de todos os sujeitos com as informaçôes do diário de campo. Dessa forma, foi possível estabelecer as seguintes categorias empíricas: a escolha da maternidade como momento crítico; o "efeito cascata" das intervençôes e as visöes sobre o parto; o momento do parto e o disciplinamento dos corpos; e a violência obstétrica e hierarquias reprodutivas.

Participaram das entrevistas 25 puérperas, com idades entre 18 e 38 anos, que receberam assistência durante o trabalho de parto, parto e pós-parto nessa maternidade. Quanto às características sociodemográficas, todas tinham relacionamento estável, a maioria residia na cidade de Porto Alegre, 52\% se identificaram como brancas e o restante como pardas e pretas (que juntas constituem a categoria negra). Podemos identificar essas mulheres como de camadas populares, sendo que o nível de escolaridade era baixo (a maioria não tinha ensino médio completo) e as atividades exercidas eram de baixa ou nenhuma remuneração: auxiliar de serviços gerais; empregada doméstica; cozinheira; operadora de caixa; "do lar". Dessas mulheres, 11 eram primíparas e 14, multíparas (50\%, acima de dois filhos). Quanto ao tipo de parto, $52 \%$ das mulheres realizaram parto normal e as demais foram submetidas à cesariana.

\section{A escolha da maternidade como momento crítico}

Nesta primeira categoria, analisamos a chegada à maternidade, que, em muitos dos casos observados e relatados pelas entrevistadas, deveu-se à escolha da gestante motivada por uma opinião positiva prévia em relação à instituição e não necessariamente por ser a maternidade de referência, conforme estipula a ERC. Algumas entrevistadas valorizaram o fato de serem aceitas nesta maternidade, 
pois antes de chegarem à instituição já haviam procurado atendimento em algum outro hospital, onde enfrentaram a demora na sala de espera e a decisão do médico de encaminhá-las de volta para suas residências.

Das 25 entrevistadas, 14 buscaram o atendimento motivadas por questóes pessoais e não pela indicação dos profissionais da saúde durante o pré-natal:

$\mathrm{O}$ posto me indicou outro hospital, mas daí achei melhor aqui. Mais pela minha mãe porque ela já teve um aqui e um lá no $\mathrm{H}^{2}{ }^{2}$ e ela preferiu esse. Daí eu fui na opinião dela (Madalena, 26 anos).

As entrevistadas relataram também situações relacionadas às vivências de partos anteriores, que contribuíram com a escolha da maternidade:

$\mathrm{Ai}$, eu gosto. Tanto que eu não queria o $\mathrm{H} 2$, eu queria esse. É que eu tive um, aí eu perdi com seis meses por culpa dos enfermeiros de lá. Faz sete anos. Aí eu não conseguia mais estar lá. Daí eu vim pra cá (Catarina, 33 anos).

O episódio trágico da morte do bebê, mencionado por Catarina, coloca em suspeita as práticas de profissionais da saúde de outra maternidade e a leva à escolha desta maternidade. Dentro de um modelo institucionalizado de parto, a procura pelo hospital se torna um momento crítico para as mulheres, pois elas se sentem apreensivas em relação a sua sobrevivência e à de seu filho. As mulheres ficam preocupadas com o que pode acontecer caso náo seja efetivada a sua internação na maternidade. A busca pelo hospital é impulsionada pelo desejo de encontrar uma assistência que lhe ofereça acolhimento e segurança (ARMELLINI; LUZ, 2003).

Nesse sentido, conforme os relatos das entrevistadas, as experiências negativas em outras maternidades, juntamente com a opiniáo de pessoas da rede de relaçôes das puérperas, pareceram ser mais significativas para escolher a maternidade do que as orientaçôes dos profissionais de saúde. Em pesquisa realizada em sete municípios do país, foi identificada a importância dos fatores subjetivos relacionados à escolha pelo local de assistência, que envolve a percepção da qualidade do serviço prestado no pré-natal e a necessidade de segurança no momento do parto. Entre esses fatores encontra-se a experiência relatada por um familiar ou conhecido que foi atendido previamente neste local (ALMEIDA; TANAKA, 2009).

A maternidade pesquisada apareceu, no nosso estudo, como sendo reconhecida positivamente por "aceitar todo mundo", inclusive à revelia dos profissionais. Durante as observaçóes na emergência do hospital, registramos 
uma situação que nos permitiu ver algumas das reações dos profissionais em relação à escolha das mulheres:

Gestante em início de trabalho de parto. Na consulta, foi identificada que sua idade gestacional era de 38 semanas. Na sua carteirinha de pré-natal havia um registro de seis consultas realizadas sempre no mesmo posto de saúde. Foi possível observar na carteirinha que a paciente estava na sua $4^{a}$ gestação, sendo que anteriormente teve um parto normal, uma cesárea e um aborto. A gestante estava referindo contração e dor. Então surgiu o seguinte diálogo:

- Médico: De onde você é?

- Paciente: Sou de Cachoeirinha.

- Médico: Mas então o que você está fazendo aqui? O posto onde tu fazes o pré-natal não te encaminhou para o hospital da tua cidade?

- Paciente: Sim, era para eu ganhar no H3, só que a maternidade não está funcionando por causa de uma bactéria. Daí eu vim pra cá.

- Médico: E quem que mandou você vir pra cá?

- Paciente: Eu vim pra cá porque uma amiga minha já ganhou aqui e ela disse pra vir aqui que não iam deixar de me atender, que era bom.

- Médico: É por isso que a gente fica sobrecarregado porque vocês não fazem o que é pra fazer! Tem que ir ao posto pra ver para onde vão te encaminhar! Depois reclama que o hospital está lotado, que tem gente na maca pelos corredores. Assim é fácil.

A mulher parecia constrangida e ria ao mesmo tempo. Apresentava um semblante de tranquilidade, talvez por acreditar que realmente ali ela ia ser atendida e internar se fosse preciso. Sem demora, o médico requisitou para que ela se deitasse para ser avaliada. Houve exame de toque, em que foi constatado $3 \mathrm{~cm}$ de dilatação. Depois se auscultou os batimentos cardíacos do bebê. Terminada a inspeção clínica, o médico solicitou a internação da paciente (DIÁRIO DE CAMPO).

Pode-se depreender uma atitude de depreciação do profissional em relaçáo à gestante (ela estava sendo culpada por supostamente náo conhecer o funcionamento da rede e por contribuir para o mau funcionamento) e certa banalização desse tipo de atitude por parte da mulher (parecia mais importante para ela a aceitaçáo na maternidade do que questionar o modo que o profissional a tratou). Evidencia-se uma hierarquização na relação médico-usuária, sem um processo de diálogo numa relação simétrica. Ao mesmo tempo, aparece um jogo de poder, na medida em que, tanto nesse caso quanto nas outras narrativas trazidas, a escolha das mulheres é informada por outras lógicas que se contrapóem à da rede de saúde, que define onde ocorrerá o parto por um processo organizativo intrínseco ao sistema. 


\section{$\mathrm{O}$ "efeito cascata" das intervençóes e as visóes sobre o parto}

Em relação à assistência durante o trabalho de parto e parto, a maioria das entrevistadas relatou que os profissionais foram atenciosos nos momentos de dor, por meio de palavras de conforto e apoio, por prescrever um medicamento ou orientá-las na respiração. Foram valorizadas pelas participantes as práticas não farmacológicas de alívio da dor, como uso de bola e o banho terapêutico. Muitas relataram terem usufruído desses métodos e os elogiaram, pois sentiram que as auxiliou na dilatação e nos momentos de dor durante as contrações no trabalho de parto:

Doía bastante. Tive bastante dor, mas aí assim que eu digo, né? Foi bom também que ela me deu banho, botava na bola, sempre atenciosa. Foi uma forma bem melhor de ficar ali, confortável mesmo. Ela disse que fizeram tudo que foi possível, foi ótima. A minha mãe ficou comigo o tempo todo (Madalena, 26 anos).

A alimentação durante o trabalho de parto também foi apontada como algo positivo, pois várias puérperas afirmaram terem sentido sede ou fome durante esse momento e que os profissionais foram zelosos ao oferecer alimentos leves e água:

Da outra vez quando acabou eu acho que sequei um rio quando eu pari. Sinceramente. E aqui não, eu tomei água, eu comi, tudo normal. Eu me senti até mais forte porque no outro eu fiquei tão fraca, mas tâo fraca que eu achei que eu nem ia viver sinceramente (Inês, 32 anos).

Com base nos dados dos prontuários e dos relatos das entrevistadas, verificouse que 11 mulheres passaram pela indução de parto, através da administração de ocitocina por via intravenosa ou por comprimido via vaginal. Todas elas afirmaram que a indução fez com que as contraçóes e a dor ficassem mais intensas, difíceis de serem toleradas. Mesmo assim, as puérperas entenderam que a indução faz parte do trabalho de parto. Compreenderam como algo doloroso, mas necessário para o nascimento:

Ai, essa [a indução] foi a pior parte! Eu tenho que lembrar mesmo? (risos). Sinceramente ela é horrível, ninguém merece ela. Eu sei que é pra ajudar a gente, eu entendo, mas, ai, é muito complicado, deixa a gente exausta, muito cansada (Inês, 32 anos).

Intervençôes como episiotomia (corte no períneo), amniotomia (ruptura artificial da bolsa) e exame de toque também foram encontradas nos prontuários e nas entrevistas. Constataram-se três episiotomias do total de 13 partos normais realizados. A amniotomia foi relatada por quatro puérperas e o exame de toque foi feito em todas as mulheres participantes: "eles botam os 
1172 dedos lá pra ver quanta dilatação tu está. Eu estava com quatro. Aí furaram a minha bolsa" (Elisabete, 24 anos).

Houve cinco lacerações espontâneas com suturas, sendo interessante observar que duas episiotomias e três laceraçóes ocorreram entre as mulheres que haviam passado pela indução de parto. Além disso, cinco dessas mulheres que receberam indução tiveram parada de progressão e acabaram realizando cesárea.

Todavia, para essas mulheres todas as intervenções médicas foram consideradas parte da "boa assistência", pois acreditaram que essas açôes tiveram o intuito de auxiliá-las da melhor forma possível, fazendo com que o momento do trabalho de parto e parto acontecesse mais rapidamente, diminuindo o sofrimento e não trazendo riscos para ela e o recém-nascido: "tudo pro bem da gente, nada é pro mal, se fosse pro mal não iam fazer" (Daniela, 31 anos). O uso de numerosas técnicas na assistência ao parto parece trazer uma ilusão tanto para os profissionais quanto para as parturientes de que quanto mais intervençôes forem feitas maior será a segurança e menor o risco de complicações (DAVIS-FLOYD, 2001).

Estudos mostram que a parada (distócia) de progressão é muitas vezes diagnosticada quando o tempo do trabalho de parto não é respeitado (CAUGHEY et al., 2014; DIAS et al., 2008). O que se percebe é que as intervençôes médicas geram um "efeito cascata", ou seja, os profissionais adotam intervençôes que podem levar a complicações, desencadeando mais intervenções subsequentes e mais complicaçôes, que terminam em uma intervenção final, em geral uma cesárea (FOGAÇA et al., 2007; MAIA, 2008).

Desse modo, observa-se que as mulheres que chegaram ao hospital apresentando poucas contraçôes ou a ausência dos sintomas do trabalho de parto estiveram mais submetidas a intervençôes e tiveram mais laceraçôes quando comparadas às mulheres que chegaram ao atendimento já em trabalho de parto ativo. Pesquisas como a de Oliveira et al. (2008) e de Schneck e Riesco (2006) mostram que, idealmente, mulheres com gestaçóes de baixo risco e que não estáo na fase ativa do trabalho de parto ( $\leq 5 \mathrm{~cm}$ de dilatação) não deveriam ser admitidas na área de pré-parto, pois correm o risco de passarem por procedimentos desnecessários. Não compreender as particularidades de cada mãe e bebê pode levar a uma aceleração no trabalho de parto, quebrando o equilíbrio da parturição fisiológica.

Além disso, é uma situação que aumenta o estresse da mulher, tornando a sensação de dor e o toque intoleráveis. Essas práticas realizadas 
indiscriminadamente podem provocar uma visão negativa da mulher em relação ao parto normal, produzindo uma ideia de que a dor no trabalho de parto é insuportável, principalmente quando esta é provocada pela ocitocina sintética:

Eu pedi ajuda. A dor estava terrível demais. A dor vinha mais por causa do soro. Se tivesse tirado o soro eu náo tinha sentido tanta dor [...] estouraram a minha bolsa $\mathrm{e}$ botaram os dois soros e ela disse que não era pra tirar (Elisabete, 24 anos).

A experiência negativa de um trabalho de parto influenciou uma puérpera a não se sentir capaz de passar por essa experiência novamente, preferindo dessa vez fazer a cesariana:

Prefiro cesárea, porque parto normal é complicado, por medo da dor. Porque eu senti a dor do parto normal sem dilatar, pra ela nascer. Eu acho que eu não ia conseguir fazer parto normal. Acho que eu ia gritar errado, eu ia fazer a força errada, acho que eu não ia conseguir. Tem que ser valente mesmo para fazer parto normal (Juliana, 31 anos).

Estudos como o de Domingues et al. (2014) mostram que experiências anteriores negativas com o parto vaginal têm sido apontadas como fator de forte associação com a demanda por cesariana.

Houve uma opiniáo singular de uma das participantes em relação à ausência de uma intervenção, o enema, que deixou de ser uma prática rotineira:

Eu preferia que continuasse a lavagem. Porque é higiênico tanto pra nós quanto pra criança, não fica aquela bagunça em cima da maca, é uma nojeira! Do primeiro eu fiz e adorei, foi muito bom! Se eles quisessem fazer em mim eu faria (Daniela, 31 anos).

Esse relato mostra que em ações tidas como "humanizadoras", quando estas viram "norma" sem ouvir as mulheres, a incomunicabilidade continua presente. Nesse caso, a vontade da mulher era que fosse feito o enema, para um maior bem-estar dela.

\section{O momento do parto e o disciplinamento dos corpos}

Para as mulheres que tiveram parto normal, o mais complicado na hora do parto foi se deslocar da maca em que estavam na sala de pré-parto para a maca da sala de parto e ter que ficar na posição de litotomia para parir: “'Oxente'! Aí foi complicado. Por causa da dor. Aí no intervalo de uma contração pra outra a gente passou pra outra maca" (Lídia, 37 anos); "A perna adormeceu de ficar daquele jeito. Mas tem que fazer força, né" (Margarida, 36 anos). 
Algumas mulheres afirmaram que sentiram vontade de se movimentar enquanto faziam força, no entanto, acreditaram que a posição em que ficaram devia ser a melhor, pois havia sido orientada pelos profissionais:

É muito complicado ficar de perna pro ar. Mas sinceramente eu acho que eu não vejo outra. É uma posição desconfortável, mas acho que não tem outra melhor pra ganhar nenê. Acho que é essa mesmo, não existe outra. Até porque se já existisse já teria sido usada, né? Mas não, não existe (Inês, 32 anos).

Mas aí não pode [mudar de posição], porque em todos os hospitais é do mesmo jeito, então onde um mudar os outros vão mudar também, mas enquanto isso não acontecer vai continuar a mesma coisa, o que é bem complicado. Tu sai da maca pra enfiar as perna lá em cima, ai meu Deus (Daniela, 31 anos).

Verificou-se que as mulheres que vivenciaram o parto normal sentiram no próprio corpo que outras posturas poderiam facilitar ou ser mais confortáveis na fase expulsiva. Todavia, também entenderam que os profissionais são os que sabem o melhor a ser feito. Esse entendimento está vinculado às relaçôes hierárquicas dentro do hospital, que colocam as mulheres num lugar passivo, limitando o espaço no qual podem se expressar e ter liberdade de conduzir o parto conforme sua vivência no corpo.

Segundo Foucault (2010), a partir do momento em que o hospital foi concebido como um instrumento de cura, a distribuição do espaço tornou-se um instrumento terapêutico (os corpos são inseridos em um espaço individualizado, controlado), os corpos são disciplinados conforme a normatização da instituição e o médico passa a ser o principal responsável pela organizaçáo hospitalar. Nessa lógica, podemos interpretar o disciplinamento dos corpos apontado pelas entrevistadas.

Já para as puérperas que realizaram cesariana, não poderem visualizar o que estava acontecendo e a sensaçáo da anestesia foram os fatos mais destacados no momento do nascimento: "Passei um pouco mal por causa da injeção. Eu senti enjoo e tontura. Tu não enxerga nada ali. Não está vendo nada. Então tu não sabe como é que está o bebê" (Cássia, 33 anos).

Pôde-se perceber que, independentemente do tipo de parto, as mulheres expressaram o desejo de participar. As puérperas que realizaram cesárea passaram pela angústia de "não poder ver nada", tendo que esperar o momento em que o filho iria dar o primeiro choro. As que tiveram parto normal podiam "ver tudo", mas também esperaram para ser conduzidas pelos profissionais sobre qual seria 
a próxima etapa. Consequentemente, o sentimento das puérperas mais citado no desfecho do parto foi o de alívio. Para as que vivenciaram o parto normal, o sentimento de alívio estava ligado ao fim da dor e para as que passaram pela cesárea, o alívio estava associado ao fato de o filho ter nascido bem.

Quanto ao contato pele a pele imediato da mãe com o recém-nascido, constatouse que ocorreu predominantemente entre as mulheres que tiveram parto normal. Algumas comentaram que logo que o filho nasceu já foi para os seus braços e deu a primeira mamada. As mulheres que vivenciaram uma cesárea relataram que viram o filho, mas só puderam ficar perto dele depois de ser examinado pelos pediatras. Quem teve o primeiro contato com o filho foi o acompanhante: "Ele [marido] sempre fica mais com ela que eu. Ainda mais cesárea, que tem que ficar costurando, ficar ali até terminar tudo” (Veridiana, 31 anos).

As observações realizadas na sala de parto se aproximam com o que foi relatado pelas puérperas. Conseguimos acompanhar tanto um parto normal quanto uma cesariana e identificou-se que as "boas práticas de atenção ao parto e nascimento" acontecem de forma fragmentada. No parto normal, a posição da parturiente era de litotomia, em um ambiente equipado com diferentes tipos de ferramentas e cercado por profissionais. Autores mostram que essa posição horizontal está relacionada com o processo histórico de medicalização do parto na medida em que favorece a visualização do profissional, sem levar em consideração o que seria mais confortável para a mulher (MAIA, 2008; DOMINGUES; RATTO, 2008).

Cabe destacar que as Diretrizes Nacionais de Assistência ao Parto Normal (BRASIL, 2017) apontam para os profissionais incentivarem as parturientes a adotar a posição que elas considerem mais confortável (cócoras, lateral, quatro apoios). Ainda, é recomendado desestimular as posiçóes horizontalizadas (como a de litotomia) e estimular as posições verticalizadas durante o trabalho de parto e parto, pelos benefícios para a mulher e para o feto (LEAL et al., 2014).

Foram vistos a realização da Manobra de Kristeller e o corte imediato do cordão umbilical, práticas desaconselhadas na atenção ao parto (WHO, 1996; BRASIL, 2017). Contudo, práticas consideradas "humanizadas” também foram observadas como: a presença do acompanhante ao lado da parturiente; o incentivo da obstetra com afirmativas positivas de que a paciente iria conseguir; o contato imediato pele a pele da mãe com o recém-nascido (BRASIL, 2017). 
$\mathrm{Na}$ cesariana, verificou-se que a mulher era monitorada constantemente pelo anestesista e que na sala ficaram vários profissionais assessorando a cirurgia. Não houve diálogo entre os profissionais e a gestante. Depois que a criança foi retirada do ventre, somente informaram que havia nascido e que estava tudo bem. Náo mostraram o bebê para a parturiente, entregando-o direto para o pediatra, que rapidamente retirou-se da sala. Portanto, náo houve contato imediato pele a pele da mãe com o bebê. Quando os profissionais estavam terminando a sutura dos cortes da cesárea é que o pai da criança apareceu com o filho e o mostrou para a máe.

Estudos mostram a importância do contato pele a pele na primeira hora de vida, seja ele por parto vaginal ou por cesárea, para promover a amamentação, assim como apontam para potencial benefício fisiológico para lactentes durante a transição para a vida extrauterina (MOORE et al., 2016).

$\mathrm{Na}$ assistência pós-parto, as puérperas avaliaram que os profissionais da enfermagem ajudaram nos cuidados com o bebê. Algumas puérperas ressaltaram a possibilidade de poder ficarem em tempo integral com acompanhante no alojamento conjunto, inclusive com o marido, pois em alguns hospitais isso não é permitido: "Eles deixam a gente ficar com acompanhante no quarto. Minha mãe passou o dia comigo e o meu esposo dorme comigo" (Adriana, 22 anos).

As observaçóes realizadas no alojamento conjunto mostraram que este foi o setor que mais buscou fornecer um atendimento acolhedor, apresentando uma relação afetiva com as puérperas nos cuidados com elas e com os bebês. Percebeuse uma grande preocupação dos profissionais em incentivar o vínculo mãe-bebê e o aleitamento materno. Como se o corpo da mulher fosse mais bem cuidado quando se transforma em "corpo de mãe".

As entrevistadas valorizaram a presença do acompanhante no momento do trabalho de parto, parto e pós-parto, sendo vista como um diferencial no atendimento, já que para algumas delas, isso não foi permitido em partos anteriores. Relataram que poder ter um acompanhante trouxe mais confiança e segurança nesse momento: "É muito bom. Te passa mais segurança. Saber que tu não está sozinha. $\mathrm{O}$ conforto do familiar sempre é especial” (Margarida, 36 anos).

Apenas três puérperas não conseguiram estar com um acompanhante, porque os maridos náo chegaram a tempo. Além disso, houve duas puérperas que contaram com a presença do acompanhante, mas uma preferiu ficar sozinha no momento do parto e a outra disse que só achou bom porque era uma cesárea: 
Eu prefiro passar por isso só com o pessoal médico sinceramente. É a primeira vez que ele me acompanha. Eu nunca gosto! Acho que é uma hora que é mais da gente, do bebê e dos médicos. Não gosto muito de acompanhante. Mas ele não assistiu o parto. Daí eu já não deixei. Aí já é demais pra mim (Lídia, 37 anos).

Eu acho que às vezes, dependendo, tipo, parto normal, eu acho que atrapalha mais ter acompanhante do que cesárea. Cesárea eu acho que é tranquilo. Tu te sente mais amparada (Helena, 31 anos).

Resultados da pesquisa Nascer no Brasil mostram que, apesar de ser garantida por lei, desde 2005, a presença de acompanhante nem sempre é efetivada nas maternidades. As mulheres com menor renda e escolaridade, negras, usuárias do setor público, multíparas e que passaram por parto vaginal apresentam menor chance de ter acompanhante, apesar de sua presença estar associada com ambiência adequada e regras institucionais nítidas sobre os direitos das mulheres ter um acompanhante (DINIZ et al., 2014). No nosso estudo, pode-se perceber que a presença do acompanhante foi garantida para as mulheres.

Ainda, é importante considerar que no caminho de tornar mais simétrica a relação entre profissionais e gestantes, abranger a diversidade de escolhas das mulheres que, nesse caso, vai além da garantia de ter a presença do acompanhante, torna-se central. Dias e Deslandes (2006) ressaltam a importância de não se adotar uma perspectiva normativa da humanização da assistência, pois se corre o risco de provocar a imposição da presença do companheiro.

\section{Violência obstétrica e hierarquias reprodutivas}

As entrevistadas relevaram situaçóes inconvenientes, geralmente relatando o episódio como uma questão pontual com algum profissional em específico e não com a instituição como um todo:

Eu acho que o atendimento em si está bom, claro que tem profissionais que às vezes tu olha que não estão nos seus dias, não estão nas suas horas, mas isso acontece. Leva muito a ponta de faca quem quer. Às vezes tu vê, olha, e tem tanta coisa pra se preocupar no momento que não dá tempo de tu considerar (Luzia, 26 anos).

Durante as observaçóes na sala de pré-parto, foi possível presenciar uma das técnicas de enfermagem falando com uma das parturientes de forma ríspida para que ela parasse de gritar. A técnica terminou sua fala dizendo que era possível não gritar, visto que nenhuma das outras mulheres estava fazendo "fiasco". Nos relatos das puérperas, uma situação semelhante foi mencionada por uma delas, 
que ficou irritada com o modo que a trataram, mas enfatizou que foi somente uma profissional que teve essa atitude:

Só foi ruim quando estava aumentando as contraçôes. Eu não conseguia não gritar, daí a mulher falava: "se tu continuar gritando a gente não vai te atender porque tu não está escutando a gente." Senti muita raiva porque eu não tinha como não gritar. Estava doendo demais! Daí falavam: "não faz fiasco que eles não te atendem direito." E ela não vinha mesmo atender. Foi uma enfermeira, mas foi só uma (Ângela, 19 anos).

Questóes como essas são características de uma violência obstétrica, sendo exercida uma depreciação, por parte dos profissionais, que coloca as mulheres em uma situação de inferioridade (DINIZ; CHACHAM, 2002). Entretanto, como foi analisado por Aguiar (2010), as mulheres consideram isso normal e até esperam ouvir comentários desse estilo em uma maternidade pública. Segundo a autora, existe uma banalização da violência (AGUIAR, 2010).

Apesar de esse tipo de postura profissional ter sido verbalizada por somente uma das entrevistadas, a maioria das puérperas deixou transparecer a ideia de que o grito deve ser evitado, porque incomoda, porque é escandaloso e pode resultar num mau atendimento dos profissionais. Trata-se de uma ideia baseada nas experiências de mulheres próximas das puérperas ou nas vivências de partos anteriores:

Sempre me diziam em casa: "olha não faz fiasco que elas te deixam por último né." É o que a gente sempre escutava lá em casa. [...] Da outra vez, no outro hospital, eu estava com aquele soro já, que começa a dilatar "né", senti a dor. Mas eu estava tranquila, porque a gente tem aquela preparação com as amigas que dizem: "não faz fiasco que elas não gostam" (Janaína, 31 anos).

Segundo Aguiar (2010), a rejeição ao ato de gritar não acontece apenas por causa de uma reproduçáo da ideologia de naturalização da dor do parto, mas também pelo medo de sofrer represália dos profissionais. Além disso, trata-se de um pensamento comum, que é passado entre as mulheres da família, amigas e outras mulheres próximas de que fazer escândalo gera mais sofrimento ao receber a assistência.

Foi possível observar que as mulheres esperavam por um "mau atendimento" no SUS, na medida em que no atendimento público de saúde o normal seria que os profissionais não as tratassem bem e que a estrutura fosse precária. Essa ideia parece ter efeitos, fazendo com que as usuárias valorizem a assistência que estão recebendo, independentemente de situaçóes agressivas de algum profissional. 
Lá no outro hospital eu não estava tendo o recurso que eu tive aqui. Eu nem imaginei que seria tâo bom sabe? Porque a gente acha que todo hospital é igual. Eu estava esperando o ruim. Mas é bom a gente esperar o ruim porque quando a gente chega aqui a gente acha que é o paraíso. Mas foi muito bom (Camila, 18 anos).

Dias e Deslandes (2006) mostram que mulheres que são atendidas em hospitais públicos tendem a ter um menor nível de exigência em relação ao que poderia ser considerado um atendimento de qualidade.

A partir do apontado neste tópico e nos anteriores, podemos pensar na existência de hierarquias reprodutivas (MATTAR; DINIZ, 2012), que provocam situaçóes de violência obstétrica vivenciadas por mulheres de camadas populares, muitas delas negras, usuárias de maternidades públicas. Seja na repressão da dor através de ameaças; seja na deslegitimação por "não conhecer o funcionamento da rede", como foi o caso apontado na discussão sobre a escolha da maternidade; seja num sentido mais disseminado na instituição, como o uso abusivo de intervençôes obstétricas sem refletir sobre a sua real necessidade e os efeitos negativos nas experiências das mulheres (potencializando dores, desconfortos, medos).

\section{Consideraçôes finais}

A partir dos relatos das puérperas e das observaçóes realizadas, verificouse na instituição pesquisada a adesão a "boas práticas de atenção ao parto e nascimento" recomendadas pelo Ministério da Saúde, como o uso de métodos não farmacológicos de manejo da dor e a presença do acompanhante durante o trabalho de parto e parto/nascimento. Essas medidas foram reconhecidas pela maioria das entrevistadas e contribuíram para que tivessem uma boa percepção da assistência recebida, o que mostra a importância de promover tais práticas.

No entanto, também foi observada uma abundância de práticas tecnocráticas de atenção ao parto. Persiste o uso rotineiro de intervençôes obstétricas, como a amniotomia e a indução do parto por ocitocina sintética. As mulheres são colocadas em um lugar passivo no processo de parturiçáo e os profissionais mantêm o seu status de autoridade, estabelecendo assim uma relaçáo verticalizada e despersonalizada. Dessa maneira, percebeu-se uma fragmentação das práticas de humanização, parecendo mais orientadas a alcançar certas metas exigidas pelo Ministério da Saúde do que para uma mudança de modelo de assistência, com dispositivos que potencializem a autonomia das mulheres em relação a como querem vivenciar seu parto. A humanização aparece atrelada a protocolos de 
procedimentos no manejo do parto e à inflexibilidade frente a eles, como se percebeu no exemplo do enema ou na aceitação da gestante para internação à revelia do profissional que a atendeu. As práticas de alguns profissionais e os relatos de algumas puérperas denunciaram uma assistência que é tecnicista e muitas vezes intimidadora, chegando a configurar casos de violência obstétrica.

Assumimos, neste artigo, que a humanização exige uma transformação profunda do modelo de assistência, da relação dos profissionais da saúde com as gestantes e parturientes, produzindo uma intersubjetividade que favoreça uma relação mais simétrica, que estimule o protagonismo da mulher no processo de parto/nascimento e que garanta seus direitos a uma parturição segura e prazerosa, para além do cumprimento de normativas, protocolos e metas institucionais. Neste estudo, entendemos que as experiências de assistência ao parto e nascimento apareceram como "à margem da humanização", na medida em que não foi percebida uma transformação mais profunda, apenas certas práticas fragmentadas que apontavam nessa direção. Caberia questionar se essa é uma realidade similar a outras instituições públicas, e se a ERC se torna uma política eficaz para promover essa mudança de modelo de assistência ao parto no Brasil. ${ }^{3}$

\section{Referências}

AGUIAR, J.M. Violência institucional em maternidades públicas: hostilidade ao invés de acolhimento como uma questão de gênero. 2010. 215 f. Tese (Doutorado em Ciências) Faculdade de Medicina, Universidade de São Paulo, São Paulo, 2010.

ALMEIDA, C.A.L.; TANAKA, O.Y. Perspectiva das mulheres na avaliaçáo do Programa de Humanizaçáo do Pré-Natal e Nascimento. Revista de Saúde Pública. São Paulo, v. 43, n. 1, p. 98-104, 2009.

ARMELLINI, C.J.; L.A.M.H. Acolhimento: a percepçáo das mulheres na trajetória da parturição. Rev Gaúcha Enferm. Porto Alegre, v. 24, n. 3, p. 305-315, 2003.

AYRES, J.R.C.M. Hermenêutica e humanização das práticas de saúde. Ciência \& Saúde Coletiva. Rio de Janeiro, v. 10, n. 3, p. 549-560, 2005.

BRASIL. Ministério da Saúde. Diretrizes Nacionais de Assistência ao Parto Normal. 2017. Disponível em: <http://portalarquivos.saude.gov.br/images/pdf/2017/marco/08/DiretrizesParto-Normal-resumida-FINAL.pdf $>$. Acesso em: 18 ago. 2017.

. Portaria no 1.459, de 24 de junho de 2011. Institui, no âmbito do Sistema Único de Saúde - SUS - a Rede Cegonha. Disponível: < http://bvsms.saude.gov.br/bvs/saudelegis/ gm/2011/prt1459_24_06_2011.html>. Acesso em: 27 set. 2014. 
CAREGNATO, R.C.A.; MUTTI, R. Pesquisa qualitativa: análise de discurso versus análise de conteúdo. Texto Contexto Enfermagem. Florianópolis, v. 15, n. 4, p. 679-684, 2006.

CAUGHEY, A. et al. Safe prevention of the primary cesarean delivery Obstetric care consensus. The American College of Obstetricians and Gynecologists. Washington, v. 123, n. 1, p. 693-711, 2014.

DAVIS-FLOYD, R. The Technocratic Body: American Childbirth as Cultural Expression. Social Science \& Medicine, v. 38, n. 8, p. 1.125-1.140, 1994.

The Technocratic, Humanistic, and Holistic Paradigms of Childbirth. International Journal of Gynecology \& Obstetrics, v. 75, 2001, p. 5-23.

DESLANDES, S.F. Análise do discurso oficial sobre a humanização da assistência hospitalar. Ciência \& Saúde Coletiva. Rio de Janeiro, v. 9, n. 1, p. 7-14, 2004.

DIAS, M.A.B. et al. Trajetória das mulheres na definição pelo parto cesáreo: estudo de caso em duas unidades do sistema de saúde suplementar do estado do Rio de Janeiro. Ciência \& Saúde Coletiva. Rio de Janeiro, v. 13, n. 5, p. 1.521-1.534, 2008.

DIAS, M.A.B.; DESLANDES, S.F. Expectativas sobre a assistência ao parto de mulheres usuárias de uma maternidade pública do Rio de Janeiro, Brasil: os desafios de uma política pública de humanização da assistência. Caderno de Saúde Pública. Rio de Janeiro, v. 22, n. 12 , p. 2.647-2.655, 2006.

DINIZ, S.G. et al. Implementação da presença de acompanhantes durante a internação para o parto: dados da pesquisa nacional Nascer no Brasil. Caderno de Saúde Pública. Rio de Janeiro, v. 30, p. 140-153, 2014.

DINIZ, S.G. Entre a técnica e os direitos humanos: possibilidades e limites da humanização da assistência ao parto. 2001.264 f. Tese (Doutorado em Medicina Preventiva) - Faculdade de Medicina, Universidade de São Paulo, São Paulo, 2001.

DINIZ, S.G.; CHACHAM, A. Dossiê Humanização do Parto. Rede Nacional Feminista de Saúde, Direitos Sexuais e Direitos Reprodutivos. São Paulo, 2002.

DOMINGUES, R.M.S.M. et al. Processo de decisão pelo tipo de parto no Brasil: da preferência inicial das mulheres à via de parto final. Caderno de Saúde Pública. Rio de Janeiro, v. 30 supl. 101-116, 2014.

DOMINGUES, R.M.S.M.; RATTO, K.M.N. II. Favorecendo parto normal: estratégias baseadas em evidências científicas. In: AGÊNCIA NACIONAL DE SAÚDE SUPLEMENTAR - ANS. O modelo de atenção obstétrica no setor de Saúde Suplementar no Brasil: cenários e perspectivas. Rio de Janeiro: ANS, 2008.

DOMINGUES, R.M.S.M.; SANTOS, E.M.; LEAL, M.C. Aspectos da satisfação das mulheres com a assistência ao parto: contribuição para o debate. Caderno de Saúde Pública. Rio de Janeiro, v. 20, n. 1, p. 52-62, 2004.

FLICK, U. Desenho da Pesquisa Qualitativa. Porto Alegre: Artmed, 2009. 
FOGAÇA, V.D.; SCHNECK, C.A.; RIESCO, M.L.G. Intervenções obstétricas no trabalho de parto em mulheres submetidas à cesariana. Cogitare Enferm. São Paulo, v. 12, n. 3, p. 296-305, 2007.

FOUCAULT, M. Microfísica do poder. São Paulo: Edições Graal, 2010.

HELMAN, C.G. Cultura, saúde e doença. Porto Alegre: Artmed, 2009.

LEAL, M.C. et al. Intervençóes obstétricas durante o trabalho de parto e parto em mulheres brasileiras de risco habitual. Caderno de Saúde Pública. Rio de Janeiro, v. 30, supl. 1, p. 1747, 2014.

LEAL, M.C.; GAMA, S.G.N. da. Nascer no Brasil. Caderno de Saúde Pública. Rio de Janeiro, v. 30, supl. 1, p. S5-S7, 2014.

MAIA, M.B. Humanização do Parto: política pública, comportamento organizacional e ethos profissional na rede hospitalar pública e privada de Belo Horizonte. 2008. $190 \mathrm{f}$. Dissertação (Mestrado em Ciências Sociais) - Programa de Pós-Graduação em Ciências Sociais/Gestão das Cidades, Pontifícia Católica de Minas Gerais, Belo Horizonte, 2008.

MATTAR, L.D.; DINIZ, C.S.G. Hierarquias reprodutivas: maternidade e desigualdades no exercício de direitos humanos pelas mulheres. Interface. Comunicação, Saúde, Educação, v. 16, n. 40, p. 107-19, jan./mar. 2012.

MOORE, E.R. et al. Early skin-to-skin contact for mothers and their healthy newborn infants. Cochrane Database of Systematic Reviews, v. 11, 2016.

MORAIS, F.R.R. A humanização no parto e no nascimento: os saberes e as práticas no contexto de uma maternidade pública brasileira. 2010. 273 f. Tese (Doutorado em Psicologia Social) - Programa de Pós-Graduação em Psicologia, Universidade Federal do Rio Grande do Norte, Natal, 2010.

OLIVEIRA, M.I.C. et al. Qualidade da assistência ao trabalho de parto pelo Sistema Único de Saúde, Rio de Janeiro (RJ), 1999-2001. Revista de Saúde Pública. São Paulo, v. 42, n. 5, p. 895-902, 2008.

RATTNER, D. et al. ReHuNa - A Rede pela Humanização do Parto e Nascimento. Revista Tempus Actas de Saúde Coletiva. Brasília, v. 1, n. 4, p. 215-228, 2010.

SANTOS, L.M.; PEREIRA, S.S.C. Vivências de mulheres sobre a assistência recebida no processo parturitivo. Physis Revista de Saúde Coletiva. Rio de Janeiro, v. 22, n. 1, p. 77-97, 2012. SCHNECK, C.A.; RIESCO, M.L.G. Intervençôes no parto de mulheres atendidas em um centro de parto normal intra-hospitalar. Revista Mineira de Enfermagem. São Paulo, v. 10, n. 6, p. 240-246, 2006.

SEIBERT, S.L. et al. Medicalização x humanização: o cuidado ao parto na história. Revista de Enfermagem UERJ. Rio de Janeiro, v. 13, p. 245-251, 2005. 
TORNQUIST, C.S. Parto e Poder: O movimento pela humanização do parto no Brasil. 2004. 429f. Tese (Doutorado em Antropologia) - Programa de Pós-Graduação em Antropologia, Universidade Federal de Santa Catarina, 2004.

VICTORA, C.G.; KNAUTH, D.R.; HASSEN, M.N.A. Pesquisa Qualitativa em Saúde Uma introdução ao tema. Porto Alegre: Tomo Editorial, 2000.

VOGT, S.E. et al. Características da assistência ao trabalho de parto e parto em três modelos de atenção no SUS, no Município de Belo Horizonte, Minas Gerais, Brasil. Caderno de Saúde Pública. Rio de Janeiro, v. 27, n. 9, p. 1.789-1.800, 2011.

WORLD HEALTH ORGANIZATION - WHO. Care in Normal Birth: a practical guide. Série Safe Motherhood. Geneva, 1996.

\section{Notas}

${ }^{1}$ Esta pesquisa foi aprovada pelos Comitês de Ética e Pesquisa da Universidade do Vale do Rio dos Sinos e do hospital coparticipante sob os pareceres de no 847.593 e no 869.574 , respectivamente. Todas as puérperas participantes do estudo assinaram o Termo de Consentimento Livre e Esclarecido e manteve-se o direito ao anonimato, através da utilização de pseudônimos para identificá-las.

${ }^{2}$ Os hospitais mencionados pelas entrevistadas foram substituídos por $\mathrm{H}$ seguido por um número sequencial (H1, H2 etc.).

${ }^{3}$ C. N. L. S. Pedroso realizou a pesquisa de campo e a elaboração geral do artigo (revisão bibliográfica, sistematização e análise de dados, escrita final). L. C. López participou da elaboração geral do artigo (revisão bibliográfica, sistematização e análise de dados, escrita final). 
Apart from humanization? Birth experiences of users of a public maternity hospital in Porto Alegre-RS, Brazil

This paper reflects on the experiences of women regarding childbirth care in a public maternity hospital in Porto Alegre-RS. It adopts a human rights perspective, understanding humanization as a broad guarantee of women's rights to a safe, socially supported and pleasurable parturition. This is an exploratory qualitative study, using participant observation techniques, semistructured interviews and documentary research. Twenty-five postpartum women, aged between 18 and 38, took part in the study. Participant reports and field records were examined through Discourse Analysis. As a result, it was identified a fragmented nature of the practices considered as "humanizing", linked to protocols of procedures in the management of childbirth and often linked to inflexibility regarding these protocols. The overrating of interventionist technologies/ practices in women's body, as well as the hierarchies between professionals and users appeared in the reports and the observations. Subjective experiences of motherhood seemed not to be considered and were left on the margins of care. It was identified specific modes of obstetric violence experienced by grassroots women, which are trivialized by the women themselves in accordance with what they expected from a public service. These situations reinforce reproductive hierarchies and end up leaving these pregnant women "on the fringes of humanization".

> Keywords: humanized childbirth; women's health; reproductive hierarchies. 